\title{
РАЗРАБОТКА АЛГОРИТМА ПО ВЫБОРУ СРЕДСТВ ОЧИСТКИ ВОЗДУХА ПРОМЫШЛЕННЫХ ПРЕДПРИЯТИЙ
}

\section{DEVELOPMENT OF AN ALGORITHM \\ FOR THE SELECTION OF AIR \\ PURIFICATION PRODUCTS \\ FOR INDUSTRIAL ENTERPRISES}

E. Evsina

N. Zolotareva

Summary. In the paper, the author presents an algorithm for choosing air purification products in order to make a decision on air purification products. The target values of the criteria depend on whether or not the user has set restrictions on the criteria for selecting filters.

For qualitative criteria, instead of target values, points are determined, which depend on the selected value from the proposed options. The target values of the criteria depend on whether or not the user has set restrictions on the criteria for selecting filters. If a restriction on the criterion was set, then the target value corresponds to one of the boundary values of the restriction (maximum or minimum, depending on the type of criterion). If there is no restriction on the criterion, then the target value is equal to zero or to the maximum value of the criterion for filters, information about which is stored in the database. The algorithm for choosing air purification products contains three algorithms.

The proposed algorithm for ensuring environmental safety provides an improvement in the quality of management activities, which makes it possible to prepare recommendations for the implementation of a set of environmental protection measures.

Keywords: algorithm, industrial enterprises, flowchart, evaluation and choice of solutions, air purification systems.

\author{
Евсина Елена Михайловна \\ К.т.н., доцент, ГАОУ АО ВО «Астраханский \\ государственный архитектурно-строительный \\ университет», Астрахань \\ evsinalena@mail.ru \\ Золотарева Наталья Валерьевна \\ К.т.н., дочент, ФГБОУ ВО «Астраханский \\ государственный университет», Астрахань \\ zoloto.chem@mail.ru
}

Аннотация. В работе автором представлен алгоритм по выбору средств очистки воздуха с целью принятия решения 0 средствах очистки воздуха. Целевые значения критериев зависят от того, устанавливал или нет пользователь ограничения на критерий для подбора фильтров. Для качественных критериев вместо целевых значений определяются баллы, которые зависят от выбранного значения из предлагаемых вариантов. Целевые значения критериев зависят от того, устанавливал или нет пользователь ограничения на критерий для подбора фильтров. Если ограничение на критерий устанавливалось, то целевое значение соответствует одному из граничных значений ограничения (максимальному или минимальному в зависимости от типа критерия). Если ограничение на критерий не установлено, то целевое значение приравнивается к нулю или к максимальному значению критерия для фильтров, информация о которых хранится в базе данных. Алгоритм по выбору средств очистки воздуха содержит три алгоритма. Предложенный алгоритм по обеспечению экологической безопасности обеспечивают повышение качества управленческой деятельности, что позволяет подготовить рекомендации на проведение комплекса мероприятий по охране окружающей среды.

Ключевые слова: алгоритм, промышленные предприятия, блок-схема, оценка и выбор решения, системы очистки воздуха.

Разработка интеллектуальной системы поддержки принятия решений (СППР) по выбору средств очистки воздуха в крупных городах является актуальной задачей. На выходе интеллектуальной системы будет набор обоснованных рекомендаций по системным упреждающим мероприятиям, направленным на недопущение развития чрезвычайных ситуаций за счет соблюдения разумного компромисса между экономико-техническими и экологическими аспектами развития региона.

В работе представлен алгоритм обработки результатов экспертного опроса с целью принятия решения 
Таблица 1. Целевые значения количественных критериев

\begin{tabular}{|c|c|c|c|}
\hline \multirow{2}{*}{$\begin{array}{l}\text { № } \\
\text { критерия }\end{array}$} & \multirow{2}{*}{ Критерий } & \multicolumn{2}{|l|}{ Целевое значение } \\
\hline & & Ограничение установлено & Ограничение не установлено \\
\hline 1 & Цена & \multirow{4}{*}{$\begin{array}{l}\text { Минимальное значение } \\
\text { ограничения }\end{array}$} & \multirow{4}{*}{$\begin{array}{l}\text { По умолчанию значение } \\
0\end{array}$} \\
\hline 2 & Ширина & & \\
\hline 3 & Длина & & \\
\hline 4 & Высота & & \\
\hline 5 & Производительность, м³/час & \multirow{3}{*}{$\begin{array}{l}\text { Максимальное значение } \\
\text { ограничения }\end{array}$} & \multirow{3}{*}{$\begin{array}{l}\text { Соответствует максимальному } \\
\text { значению критерия для всех } \\
\text { фильтров БД }\end{array}$} \\
\hline 6 & Скорость фильтрации, м/с & & \\
\hline 7 & Степень очистки,\% & & \\
\hline
\end{tabular}

Таблица 2. Баллы значений качественных критериев

\begin{tabular}{|l|l|l|l|}
\hline \multirow{2}{*}{8} & Кo критерия & Значение & Балл \\
\hline \multirow{2}{*}{9} & Способ монтажа & Требует специального монтажа & 70 \\
\cline { 2 - 4 } 9 & Не требует специального монтажа & 100 \\
\hline \multirow{2}{*}{ Режим работы } & Периодический & 50 \\
\cline { 3 - 4 } & Аварийный & 70 \\
\cline { 2 - 4 } & Непрерывный & 100 \\
\hline
\end{tabular}

о средствах очистки атмосферного воздуха промышленных предприятий. В работе разработан алгоритм по выбору средств очистки воздуха с целью принятия решения о средствах очистки воздуха [1-6].

Обработка результатов экспертного опроса производится по алгоритму, представленному ниже:

1. Формирование обобщенной оценки.

2. Определение относительных весов для каждого мероприятия по охране окружающей среды.

3. Установление степени согласованности мнений экспертов.

4. На основании выставленных оценок критериев, подбирается фильтр, ниже в таблице 1 приведен алгоритм подбора фильтров, в таблице 2, приведен алгоритм расчета баллов для фильтров.

Целевые значения критериев зависят от того, устанавливал или нет пользователь ограничения на критерий для подбора фильтров. Если ограничение на критерий устанавливалось, то целевое значение соответствует одному из граничных значений ограничения (максимальному или минимальному в зависимости от типа критерия). Если ограничение на критерий не установлено, то целевое значение приравнивается к нулю или к максимальному значению критерия для фильтров, информация о которых хранится в базе данных [7-12].

Для качественных критериев вместо целевых значений определяются баллы, которые зависят от выбранного значения из предлагаемых вариантов. В таблице 2 приведены значения баллов по умолчанию. В идеале значения баллов должны вводиться экспертами вместе с весами критериев [13-19].

Алгоритм по выбору средств очистки воздуха содержит три алгоритма:

- алгоритм экспертной оценки;

- алгоритм подбора фильтров;

- алгоритм расчета баллов для фильтров.

Рассмотрим каждый из алгоритмов более подробно.

Алгоритм работы разрабатываемой информационной системы с учетом многокритериального выбора критериев по выбору средств очистки воздуха представлен блок-схемой (см. рис. 1). 
Таблица 3. Алгоритм экспертной оценки

\begin{tabular}{|c|c|c|c|c|}
\hline Шаг & Задача & Формула расчета & Входные данные & Результат \\
\hline 1 & $\begin{array}{l}\text { Проводится } \\
\text { аддитивная сверстка } \\
\text { критериев }\end{array}$ & $a_{\mathrm{Hopmij}}^{k}=\frac{a_{i j-a_{\min j}^{k}}^{k}}{a_{\operatorname{maxj}}^{k}-a_{\operatorname{minj}}^{k}}$ & $\begin{array}{l}\text { Минимальная и } \\
\text { максимальная оценки } \\
\text { k-мнения эксперта по } \\
\text { ј-му критерию }\end{array}$ & $\begin{array}{l}\text { Проведена аддитивная свертка } \\
\text { каждой матрицы оценок, } \\
\text { заполненных экспертами }\end{array}$ \\
\hline 2 & $\begin{array}{l}\text { Расчет весового } \\
\text { коэффициента wik для } \\
\text { каждого критерия для } \\
\text { к-го мнения эксперта }\end{array}$ & $w_{i}^{k}=\sum_{j=1}^{m} a_{\text {ноpмij }}^{k} \cdot q_{j}$ & $\begin{array}{l}\text { Нормировка } \\
\text { критериев }\end{array}$ & $\begin{array}{l}\text { Весовой коэффициент для } \\
\text { каждого критерия }\end{array}$ \\
\hline 3 & $\begin{array}{l}\text { Расчет коэффициента } \\
\text { конкордации D. }\end{array}$ & $D=\frac{12 \cdot S}{L^{2}\left(n^{3}-n\right)^{\prime}}$ & $\begin{array}{l}\text { Весовой коэффициент } \\
\text { для каждого критерия }\end{array}$ & $\begin{array}{l}\text { Анализ разброса и } \\
\text { согласованности оценок }\end{array}$ \\
\hline
\end{tabular}

Таблица 4. Основные шаги алгоритма подбора фильтров

\begin{tabular}{|c|c|c|c|c|}
\hline Шаг & Задача & Краткое описание & Входные данные & Результат \\
\hline 1 & $\begin{array}{l}\text { Отбор фильтров по } \\
\text { токсикантам }\end{array}$ & $\begin{array}{l}\text { Для выбранной пробы } \\
\text { из справочника } \\
\text { фильтров отбираются } \\
\text { фильтры, которые } \\
\text { очищают от токсикантов } \\
\text { с концентрацией, } \\
\text { отклоняющейся от ПДК }\end{array}$ & $\begin{array}{l}\text { База данных всех фильтров } \\
\text { справочника }\end{array}$ & $\begin{array}{l}\text { Список фильтров, } \\
\text { отфильтрованный по } \\
\text { токсиканатам }\end{array}$ \\
\hline 2 & $\begin{array}{l}\text { Ввод критериев отбора } \\
\text { фильтров }\end{array}$ & $\begin{array}{l}\text { Пользователь по } \\
\text { интересующим его } \\
\text { критериям вводит } \\
\text { диапазоны допустимых } \\
\text { значений или выбирает из } \\
\text { предлагаемых вариантов } \\
\text { значения критериев }\end{array}$ & $\begin{array}{l}\text { Незаполненный список } \\
\text { критериев отбора фильтров }\end{array}$ & $\begin{array}{l}\text { Заполненный пользователем } \\
\text { список критериев отбора } \\
\text { фильтров }\end{array}$ \\
\hline 3 & $\begin{array}{l}\text { Отбор фильтров по } \\
\text { критериям }\end{array}$ & $\begin{array}{l}\text { Из списка фильтров, } \\
\text { отфильтрованных по } \\
\text { токсиканатам, отбираются } \\
\text { фильтры, значения } \\
\text { характеристик которых } \\
\text { соответствуют заданным } \\
\text { пользователем критериям } \\
\text { отбора }\end{array}$ & $\begin{array}{l}\text { Список фильтров, } \\
\text { отфильтрованный по } \\
\text { токсиканатам }\end{array}$ & $\begin{array}{l}\text { Список фильтров, } \\
\text { отфильтрованный по } \\
\text { токсиканатам и критериям } \\
\text { отбора }\end{array}$ \\
\hline 4 & Расчет баллов фильтров & $\begin{array}{l}\text { Расчет баллов описан в } \\
\text { таблице } 2\end{array}$ & $\begin{array}{l}\text { Список фильтров, } \\
\text { отфильтрованный по } \\
\text { токсиканатам и критериям } \\
\text { отбора }\end{array}$ & $\begin{array}{l}\text { Список фильтров с } \\
\text { рассчитанными баллами }\end{array}$ \\
\hline 6 & $\begin{array}{l}\text { Формирование отчета } \\
\text { по рекомендуемым } \\
\text { фильтрам }\end{array}$ & $\begin{array}{l}\text { Полученные данные по } \\
\text { фильтрам выгружаются в } \\
\text { отчет Excel }\end{array}$ & $\begin{array}{l}\text { Список фильтров, } \\
\text { отсортированный по } \\
\text { убыванию балла }\end{array}$ & Отчет в Excel \\
\hline
\end{tabular}


Таблица 5. Алгоритм расчета баллов для фильтров

\begin{tabular}{|c|c|c|c|c|}
\hline Шаг & Задача & Формула расчета & Входные данные & Результат \\
\hline 1 & $\begin{array}{l}\text { Расчет отклонений } \\
\text { фактического значения } \\
\text { фильтров от целевого } \\
\text { значения для критериев } \\
\text { 1-7 (см. табл. 1) }\end{array}$ & $\begin{array}{l}\mathrm{O}_{f k}=100- \\
\frac{A b s\left(Ц_{k}-\Phi_{f k}\right)}{\Phi_{k m a x}} \cdot 100 \\
\text { где } \\
O_{f k}-\text { оценка критерия } k \text { для } \\
\text { фильтра } f_{,} \\
Ц_{k}-\text { целевое значение } \\
\text { критерия } k \\
\Phi_{f k}-\text { фактическое значение } \\
\text { критерия } k \text { для фильтра } f, \\
A b s\left(Ц_{k}-\Phi_{f k}\right)-\text { абсолютное } \\
\text { значение разности между } \\
\text { целевым и фактическим } \\
\text { значением критерия, } \\
\Phi_{\text {ктах }- \text { максимальное }} \\
\text { значение критерия к среди } \\
\text { всех значений по отобранным } \\
\text { фильтрам }\end{array}$ & $\begin{array}{l}\text { 1. Список фильтров, } \\
\text { отфильтрованный по } \\
\text { токсиканатам и критериям } \\
\text { отбора } \\
\text { 2. Фактические значения } \\
\text { критериев } k \text { для фильтра f } \\
\text { 3. Целевые значения } \\
\text { критериев } k \text {, указанные } \\
\text { пользователем в критериях } \\
\text { отбора }\end{array}$ & $\begin{array}{l}\text { Оценка для критериев } \\
\text { 1-7 для каждого фильтра } \\
\text { (см. табл. 5) }\end{array}$ \\
\hline 2 & $\begin{array}{l}\text { Вычисление нор- } \\
\text { мализованного } \\
\text { фактического значения } \\
\text { критериев 8-9 } \\
\text { (см. табл. 2) }\end{array}$ & 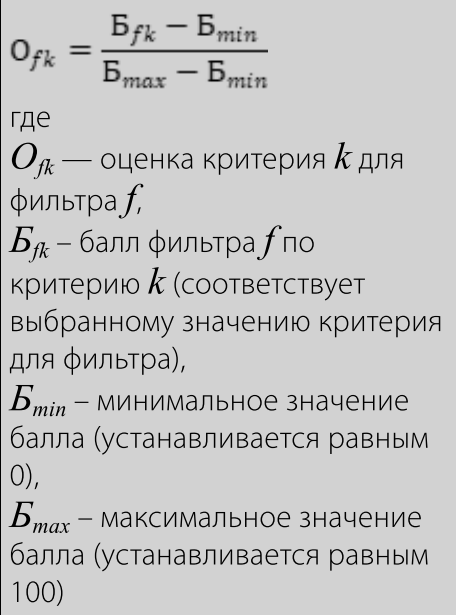 & $\begin{array}{l}\text { 1. Список фильтров, } \\
\text { отфильтрованный по } \\
\text { токсиканатам и критериям } \\
\text { отбора } \\
\text { 2. Значения баллов } \\
\text { критериев } k \text { для фильтра } f\end{array}$ & $\begin{array}{l}\text { Оценка для критериев } \\
\text { 8-9 для каждого фильтра } \\
\text { (см. табл. 5) }\end{array}$ \\
\hline 3 & $\begin{array}{l}\text { Вычисление } \\
\text { взвешенной оценки } \\
\text { критериев 1-9 }\end{array}$ & $\begin{array}{l}\text { о }_{f k}^{v}=V_{k} \cdot \mathrm{O}_{f k} \\
\text { где } \\
\mathrm{O}_{f k}^{v}-\text { взвешенная оценка } \\
\text { критерия } k \text { для фильтра } f, \\
V_{k}-\text { вес критерия } k \\
\text { (устанавливается экспертом) } \\
O_{f k}-\text { оценка критерия } k \text { для } \\
\text { фильтра } f\end{array}$ & $\begin{array}{l}\text { 1. Список фильтров, } \\
\text { отфильтрованный по } \\
\text { токсиканатам и критериям } \\
\text { отбора } \\
\text { 2. Веса критериев k, } \\
\text { установленные экспертами } \\
\text { 3. Оценки критериев k=[1..9] } \\
\text { для фильтра f }\end{array}$ & $\begin{array}{l}\text { Взвешенные оценки } \\
\text { критериев 1-9 для } \\
\text { каждого фильтра }\end{array}$ \\
\hline 4 & Расчет баллов фильтров & $\begin{array}{l}\text { Б }_{f}=\frac{\sum_{k=1}^{K} \mathrm{O}_{f k}^{v}}{K} \\
\text { где } \\
D_{f}-\text { балл фильтра } f \\
\text { O }_{f k}-\text { взвешенная оценка } \\
\text { критерия } k \text { для фильтра } f_{\text {, }} \\
K-\text { количество критериев (по } \\
\text { умолчанию 9) }\end{array}$ & $\begin{array}{l}\text { 1. Список фильтров, } \\
\text { отфильтрованный по } \\
\text { токсиканатам и критериям } \\
\text { отбора } \\
\text { 2. Взвешенные оценки } \\
\text { критериев, рассчитанные на } \\
\text { шаге } 3 \\
\text { 3. Количество критериев }\end{array}$ & $\begin{array}{l}\text { Список фильтров с } \\
\text { рассчитанными баллами }\end{array}$ \\
\hline
\end{tabular}




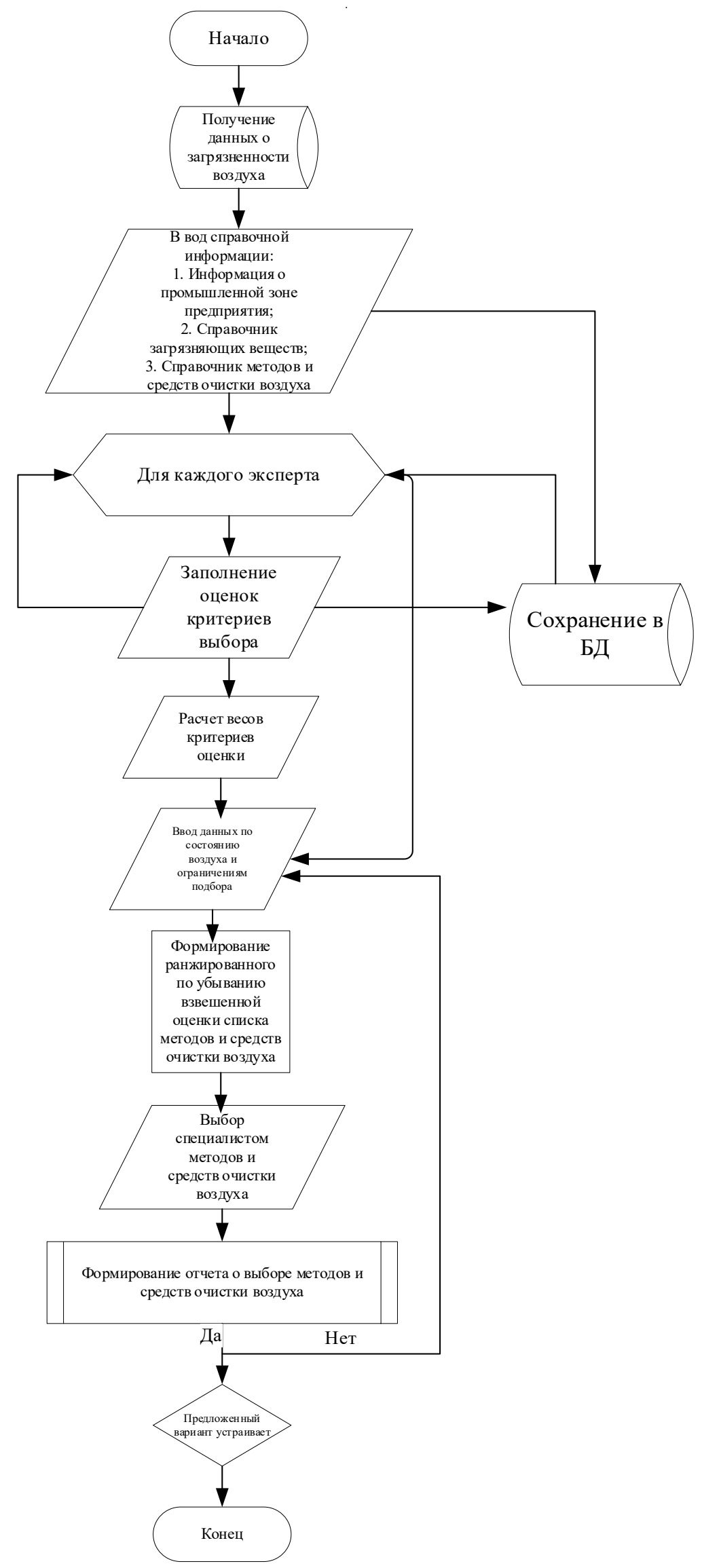

Рис. 1. Блок- схема 


\section{Зак^ючение}

1. Задача подбора средств для управления качеством атмосферного воздуха заключается в поиске альтернатив, т.е. управляющих воздействий, обеспечивающих снижение концентрации загрязняющих веществ в атмосфере.

2. Предложенный алгоритм СППР по обеспечению экологической безопасности обеспечивают по- вышение качества управленческой деятельности.

В связи с этим при подготовке рекомендаций на проведение комплекса мероприятий по охране окружающей среды целесообразно применять научно-методический аппарат определения сложности экологической обстановки, оцениваемой с помощью как объективной, так и субъективной информации.

\section{ЛИТЕРАТУРА}

1. Бурляева Е.В. Информационно-методологическое обеспечение поддержки принятия решений при прогнозировании активности конформационно-гибких органических соединений: дисс. д-ра. техн. наук: 05.13.01-М., 2004.-182 с.

2. Вагин В.Н., Еремеев А.П. Некоторые базовые принципы построения интеллектуальных систем поддержки принятия решений реального времени // Известия РАН. Теория и системы управления. 2001. № 6. С. 114-123.

3. Варшавский П.Р., Еремеев А.П. Поиск решения на основе структурной аналогии для интеллектуальных систем поддержки принятия решений // Известия РАН. Теория и системы управления, № 1, 2005. С. 97-109.

4. Гаврилов А.В. Гибридные интеллектуальные системы: Монография. Новосибирск: Изд-во НГтУ, 2002. 142 с.

5. Кудинов Ю.И., Дохоров И.Н., Пащенко Ф.Ф. Нечеткие регуляторы и системы управления. Журнал «Проблемы управления», Выпуск № 3, Инсутитут проблемы управления им. В.А. Трапезникова РАН, 2004, Москва. С. 2-14.

6. Михайлова П.Г. Разработка интеллектуальной системы поддержки принятия решений по управлению безопасностью химических производств: дис. канд. тех. наук. М.: 2006. 194 с.

7. Лёвушкина С.А. Интеллектуальная система поддержки принятия решений по управлению качеством атмосферного воздуха на химических предприятиях: дис. канд. тех. наук. М.: 2010. 186 с.

8. Егоров А.Ф., Савицкая Т.В., Дударов С.П. Использование искусственных нейронных сетей для идентификации промышленных источников загрязнения атмосферного воздуха. Часть 1. Идентификация аварийных источников загрязнения атмосферного воздуха //Химическая промышленность сегодня, 2004, № 6. С. 39-45.

9. Егоров А.Ф., Савицкая Т.В., Дударов С.П. Использование искусственных нейронных сетей для идентификации промышленных источников загрязнения атмосферного воздуха. Часть 2. Идентификация аварийных источников загрязнения атмосферного воздуха //Химическая промышленность сегодня, 2004, № 8. С. 32-41.

10. Егоров А.Ф., Дударов С.П., Лёвушкин А.С. Информационная система нейросетевого моделирования загрязнения воздуха промышленными источниками на основе генетического алгоритма обучения. Химическая промышленность сегодня, 2009, № 12. С. $21-29$.

11. Савицкая Т.В., Дударов С.П., Лёвушкина С.А., Егоров А.Ф., Лёвушкин А.С. Использование искусственных нейронных сетей для прогнозирования загрязнения атмосферного воздуха аварийными источниками при изменяющихся метеоусловиях. Экологические системы и приборы, 2007, № 10. С. 45-50.

12. Гусев Д.М., Дударов С.П. Исследование и настройка генетического алгоритма вещественного кодирования с использованием тестовой функции Швефеля // Успехи в химии и химической технологии: сб. науч. тр. Том XXVII, № 1 (141). М.: РXTУ им. Д.И. Менделеева, 2013. С. 37-42.

13. Егоров А.Ф., Михайлова П.Г., До Мань Хунг. Нечеткая система управления показателями качества продукции первичной переработки нефти // Вестник Тамбовского государственного технического университета. Том 19, № 4, 2013. С. $758-764$

14. Федеральный закон РФ от 21.07.2014 N219-Ф3 «0 внесении изменений в Федеральный закон «0б охране окружающей среды» и отдельные законодательные акты Российской Федерации».// Собрание законодательства РФ — № 30-2014. — пункт 4220.

15. Постановление Правительства РФ от 28 сентября 2015 года № 1029 «0б утверждении критериев отнесения объектов, оказывающих негативное в0здействие на окружающую среду, к объектам I, II, III и IV категорий».

16. Распоряжение Правительства РФ от 08.07.2015 № 1316-р «Перечень загрязняющих веществ, в отношении которых применяются меры государственного регулирования в области охраны окружающей среды».

17. Федеральный закон РФ от 26.06.2008 № 102-Ф3 «06 обеспечении единства измерений». 5. ГОСТ Р 50831-95. Установки котельные. Тепломеханическое оборудование. Общие технические требования.

18. РД 153-34.0-02.303-98 Инструкция по нормированию выбросов загрязняющих веществ в атмосферу для тепловых электростанций и котельных. М.: СПО ОРГРЭС. 1998.

19. Дементиенко А.В., Кузьмина Ю.А., Савицкая Т.В. Разработка баз данных информационно-моделирующей системы мониторинга и прогнозирования состояния окружающей среды // Успехи в химии и химической технологии: сб. науч. тр. Том XXVII, № 1 (141). М.: РXТУ им. Д.И. Менделеева, 2013. С. 7-12. 